\title{
The Study of Classroom Teaching Method of Social Role Theory-It Is Based On Personal Tailor
}

\author{
Mei-Nan LV'1a , Xin LI ${ }^{2 b^{*}}$ \\ 1aHarbin Finance University, No. 65, Carbon Road, Xiang Fang District, Harbin \\ $2 b^{*}$ College of Economics and Management, Shanghai Ocean University \\ 1ameinan510@hotmail.com
}

\begin{abstract}
Keywords: Social Role Classification, Social Role Performance, Social Role Playing, Social Role Imbalance, Personal Tailor
\end{abstract}

\begin{abstract}
Based on the Personal Tailor, borrowing its teaching methods to explore the social role theory, this paper focuses on teachers how to show and explain the basic knowledge of social role theory such as the content of social roles, the classification of social roles, the performance of social roles, the process of playing social roles and the maladjustment of social roles etc. in sociology classroom teaching, and how to make students understand the theoretical analysis and interpretation and be able to use it, and make them participate in class discussion actively, so that they can do the combination of theory and practice, and be able to apply the theory into practice.
\end{abstract}

\section{Introduction}

How to optimize classroom teaching to make it more vivid and more attractive to students has always been the goal of the teachers standing on the platform, and also the goal of every teacher's unremitting efforts. In sociology class, teachers are motivated to explore how to make abstract and complicated theory more specific and clearer, and convey knowledge to students vividly, so that they can understand and grasp well in the classroom. However, in previous sociology classes, the text, picture or performance of courseware were fully utilized in teaching social roles. At the end of 2013, after watching Feng Xiaogang's New Year film Personal Tailor, the author thinks that the film provides a good blueprint for the knowledge teaching of social role theory, and uses in class teaching practice of sociology, borrowing the teaching method used in the film to conduct a preliminary inquiry. It's also emphasized that the roles in the film are not the same as the reality or absolutely equal to show the characters of social roles, while teachers use the way of "graphic " based on the performance of these roles to make social role theory more "visual", so that students can understand the social role theory more intuitively and easily.

Personal Tailor, the story of a four-personal tailor company, shows that the Desire Planner Yang (played by Ge You), Situational Designer Bai (played by Bai Baihe), Dream Engineer Lu (Li Xiaolu) and Mind Anesthetist MaQing (played by ZhengKai), establish a company together to allow customers to complete the dream trip with their design, and this process through a role play, actually, is also very good to interpret the sociological role theory. In this movie, there are five stories of roleplaying. In classroom teaching, teachers use the role-playing of the story 2 goodness and story 5 rich to concrete analysis, leading students to study relevant theories of social roles in depth through the fragments.

In sociological theory teaching class, teachers use multimedia to show and explain the basic knowledge of social role theory such as the content of social roles, the classification of social roles, the performance of social roles, the process of playing social roles and the maladjustment of social roles etc. clearly, making students have a preliminary understanding and mastering to the theory, and

\footnotetext{
${ }^{{ }_{*}^{*}}$ Corresponding Author: Li xin, College of Economics and Management, Shanghai Ocean University, associate professor, Ph.D.xinli@shou.edu.cn Paper Description: This paper is funded by Shanghai Ocean University "haiyan talent" training program: A1-0209-15-2000-33.
} 
discuss and interpretant it with these two stories in the film Personal Tailor.

On this part of theoretical knowledge, the author mainly completed the teaching tasks in two ways: classroom teaching and after-school homework. In classroom teaching, the display of theory in the teaching material is used with the theory of film and detailed analysis of interpretation, leading students to be shown in the role discussed in the film. And the content of the homework after class teaching, allow students to use the knowledge that they have learned from this part of the social role theory, and analyze another story of the film illustrated so make students to do actual combat training. At the same time, it can also use this way to test the teachers' teaching effect. In addition, the teacher can also comment on the students' work and further guides the knowledge of social role.

\section{Class Explanation and Analysis}

\section{The Meaning of Social Roles}

The role comes from the drama, mainly refers to the actors play the characters, but also metaphor of life in a certain type of characters and opera actor division of labor division. Because this concept helped to understand human social behavior and personality, some scholars introduced sociology in the 1920s and 1930s. What is social role? Social role refers to a set of rights and obligations that conform to people's social status and identity. It is the behavior of people who have a specific identity, which forms the basis of a social group or organization. The social role of human beings is the status or role played by people in certain social backgrounds. Social role is external manifestation of social status and behavior patterns, in the film, Dan was generous, arrogance, dressed in expensive clothes, with the status on high, and has good behavior followed with the servant service, she played as a social role of the rich.

\section{The Type of Social Roles}

Firstly, through the way of people acquire roles, social roles can be divided into preassigned roles and self-induced roles. The role of precast is the social role based on genetic or biological factors. The role of self - making is primarily through individual activities and efforts. In the film, as the role of the rich, she hopes to achieve her rich-dream through hard work on her own, and the role should be attributed to the self-induced character. Then, she said her money was grandparents upload down, became the rich in this way, she became a rich of second generation, and this way should be relegated to the role of ascribed role.

Secondly, the social role can be divided into the roles and the open roles from the degree of standardization. The character refers to a character with a strict and explicit stipulation; an open role is a social role that is not strictly defined. In the film, the role of the rich is not clearly defined, so she played the role by her own understanding and expectations to the role, therefore it is an open role.

Thirdly, according to the goals pursued by the characters, roles can be divided into utilitarian roles and expressive roles. Utilitarian role refers to the social role that aims at the pursuit of benefits and actual interests; the expressive role is the social role that shows the social system and order, and the norms of social behavior, the value idea, the thought morality and so on. In the movie, Song Dandan plays a rich man who is engaged in various production and operation activities, and is a profit-oriented social role.

Fourth, it can also be divided into conscious roles and involuntary roles according to the psychological state of people when they assume social roles. Consciousness refers to people who played in the role clearly aware that himself is burdened with certain rights and obligations, the awareness of the role of the people around him are all his audience, and he makes efforts to use his own actions to infect around the audience; An unconscious role is when people assume a role that they don't realize they are acting as a part of it, but only as a habitual behavior. In the movie, Dan realized that she was a rich woman, and required herself act with the rich behavior, such as she said in the movie "in slam shut," so here, the role is part of the role of consciousness. 


\section{The Determination of Social Roles}

\section{Demonstrate the Determination of Social Roles}

The role of a person in the social arena has a certain process, that's to prove that a person's actual status, identity and other conditions are consistent, equivalent with the role's he played. On the social stage, people can't play any role at will. The first step to play the role of society well is to determine the social roles, and the social role is actually answered by "who I am". Only by making clear who I am, can I know what I am going to do and how to do it. If the role was determined wrongly, it will lead to most of problems like incompetence, inappropriate role consequences and failure to take on the right role.

\section{Analyze the Determination of Social Roles with the Film}

For each individual, to determine the social role, the most important thing is to answer "who am I?" In other words, in the process of answering "who I am", it is important to determine your actual position and relationship with others so that you can act as a correct role.

In the film, Dan (played by Song Dandan) constantly determines her actual status and the relationships with other people during the process of determining the role of the rich. For example, which she said, "I have had so much money that I should be fragrant, and you are my attendant, you need some perfume too." She also asked Dream Engineer Lu (Li Xiaolu) to spray some perfume, to match with her role of the rich. Of course, in the film, Dan's determination of the rich character is different from the determination of social roles. In the film, the Desire Planner Yang (played by Ge You) and Dream Engineer Lu (Li Xiaolu) determine Dan's "social character "clearly firstly, telling who she is, what kind of her character is. She is the richest man in south Beijing, and she needs to know that the role of the rich should do: look at the global market in the morning, and then look the notes, including the euro, the dollar price. We found that at the beginning, Dan couldn't make sure the role of the rich, and she said she didn't understand Yang's words, and she had no money. Then, Lu told her to build confidence and at the same time, let her say one hundred times" I am a rich man. "In mind. In the end, Dan determines her identity that she was outbreak to be rich. So, we can see that the film's role was defined by others' help. However, the social role of reality including selfconfirmation and social confirmation. In the film, people helped Dan to clear her new role is a rich woman not an ordinary person, in order to better play the new role, control the new character, and finally be competent the role of qualified for the wealthy. And the determination of social role is to make everyone play the social role well in social life.

\section{The Performance of Social Roles}

\section{The Clothes, Props and Behaviors of the Social Roles}

\section{Show the Relevant Theories}

How do you represent a social role after an accurate positioning of the character? The performance of a social role is like a theatrical performance. William Shakespeare, the great British dramatist, discovered the inner connection between the social stage and the theatre. He said in his works All's Well That End Well in such a famous saying: the world is a stage, and all the men and women are actors. They have their own import and export; a person plays many roles in life". "Play likes life, life is a play", the drama and life have some similarities. There are sets for theatrical performances, and there is a social context in sociology. There are actors on stage, there are social people in society. Both in play and in the society, props, clothes, appearance, language, and behavior are not less, that's to say, from the clothes and the manners, we can know the person's social role.

\section{Use the Film to Interpret the Set Props, Clothes and Manners}

Setting and props, clothes, appearance and mannerisms are very important in the performance of social roles, which can not only create situations but also help people to better enter the situation and show social roles. On the scene props in the film, to show the life of the rich environment, set up a 
palatial mansion, expensive luxury cars, the welcome crowd, walk in and out of the high-end market, sales offices, and all the symbolic meaning of things, build a rich life situation.

There is a saying in China that "the man's clothes, the horse's saddle" speaks volumes about the importance of dressing for the role. Dan got into the palatial residence, as the image of a servant, Lu moved to Dan and said "play for you", and dressed up for her. When she looked at her new face, she was startled. Continually, Lu let her wear the dress, wear a pearl necklace, and chose a white handbag for Dan. After dressing up, she looked like a lady. But that's not enough, Yang also trained her to raise her hands and make her behave like a nobleman. Thus, the scenery and props, clothes, appearance and mannerisms are important to the performance of the characters.

\section{The Front Desk, Background Theory of the Role}

\section{Show the Front Desk and Background Theory of the Role}

Like the performance of the stage and the stage in the drama performance, the performance of the social role in the front desk and the back stage are also different. The actor plays on stage, according to the script, even if acting in the stage is, returning to the life in the backstage. Social life is also the same, when the judge robes off, he can perspective on the case as the common people, comment on the case itself with the language of the civilian character, at this time, his role converted to ordinary people, and he has his own values and thoughts and feelings. As the justice in the front desk, enforce the law impartially, while foreground and background is different, the role also has carried on the transformation of behavior and words.

\section{Use the Film to Analyze the Performance of the Foreground and the Background}

When Dan was playing the role of lady, following with her attendant to look at the real estate, to go shopping, she showed her generous as a rich woman in the manners and words. This is the front role. The atmosphere and the atmosphere of the rich are the front desk, which is a sign of the social role of the rich. As a rich person, at home every day, she need to look at the stock market changes, the world's financial situation, and to make up, maintain, practice good manners, etc. This is a manifestation of the background, which is in order to have confidence at the front desk. But both foreground and background, all need cooperation between different roles. For example, Dan have the bustling serve followed, bodyguard of personal protection, and there are also the sales offices' and the staff' flattery, so the cooperation between these roles make the social role more realistic.

\section{The Process of Playing Social Roles}

\section{Demonstrate the Theory of Role-Playing}

How can social roles be achieved in society? This needs to be done through role-playing. The role played by people in social life is not simply the exercise of the role, but rather a role plays or the role creation. In this process, the actor is not passive to be subject to the situation and structure, he can also define the situation and influence the social structure through interaction. What is role-playing? When the role of the individual interact with a role partner under certain conditions in accordance with the rights and obligations of a certain social role, the individual is role-playing.

There are three stages in the social role-playing process: role expectation, role understanding, and role practice. Role expectation, also called role expectancy, refers to the expectations and requirements of a society for a role. The role expectations people face can be divided into different levels: general expectations and special expectations. If the role expectations are unclear, there are many problems with role-playing. Role recognition is also known as role cognition, which refers to the understanding and understanding of the role norms and role requirements of the role play. For the same role, the role expectation is generally the same, while the role perception is different. It is because that the different perceptions of the same character makes the role of the society varies widely. Role practice is also called role behavior, which is the actual process or activity of role play, and the development of role understanding. In general, the role awareness is consistent with the role practice, but sometimes there are deviations.

The role of people in the real performance, is the expected role (external) social concepts, under 
the guidance of understanding role (internal personal ideas), under the domination of the practice role of (inside and outside the combination of individual action). Due to the constraints of subjective and objective factors, there will inevitably be some gap between the role of practice, the understanding of roles and the expected roles, which also leads to the smooth or not in the process of social role playing.

\section{Use the Film to Analyze the Theory of Role-Playing Process in Detail}

In the film, "Four rounds of dreams" hope Dan can play into the role as soon as possible, and can truly experience of the rich life from the heart to act, this is the role expectation of "Four rounds of dreams". But Dan comprehended different about the role of the rich, from the beginning, she was tangled about how to get her own one hundred billion, and asked them to give her a statement, however, she hoped her fortune was accumulated, or had been passed down from ancestors. In a word, she was completely ignorant of how the rich get rich, but in the end, she really feels that the rich have not had her day. Because of the change of the understanding of the role norms and role requirements of the rich, it leads to the deviation of the role practice. For example, she opened the door herself but was told that she didn't have to do it herself, and when she did follow the "man to the door" principle, she bumped into the door. When she got out of the car, she said thanks to the attendant, but Yang asked her to do it again. Then, as the life of the rich slowly gets deeper, the role practice reduces the bias. From the end of the film, the Desire Planner Yang (played by Ge You) said to her on the road, "I was afraid that you couldn't get into the play, but I didn't expect you to live up to your kindness." It is not hard to see that the realization of this "social role" is a process of role-play, including the role's expectation, the understanding of the role, and the practice of the role.

\section{The Maladjustment of Social Roles}

In social life, the role of people is in the guidance of the ideal role and the role of practice under the control of the understanding role. But the role of society is unlikely to be favorable. In the role-play of social roles, there will inevitably be contradictions, obstacles and even failures, which means that in many cases there is a gap compared with the expected role, and sometimes with the understanding role. Sociology calls this gap the role gap or role distance or role dissonance. Depending on the extent of the disorder, we can divide it into four categories: role conflict, role ambiguity, role disruption, and role failure.

\section{Role Conflict}

\section{Show the Relevant Theories}

Role conflict refers to the contradiction, antagonism and conflict between roles or characters, hindering the smooth progress of role play. Role conflict has two types, one is the conflict between roles, the conflict between different roles' risk-takers, the other one is the conflict within a same role, a variety of social role of individual own internal conflicts. One of them is that when a person takes on a variety of social roles, inevitably the phenomenon of attending to one thing and losing another.

\section{Use Film Analysis to Interpret Character Conflict}

In the movie, Dan, accompanied with his attendant, went shopping at the mall and saw the Songhe Lou hotel, she ran to the restaurant and shouted, "eat it, I'll buy it today." At this time, she clashed the rich role with her real civilian role, showing that the rich man will ask for a stranger to have a meal, but with the condition of the poor, it is not allowed to do this in real life, and these two roles conflict. This is due to the opposing roles of both rich and poor.

\section{Role is not Clear, Role Interruption}

\section{Show the Relevant Theories}

The role of a character is not clear means that people don't know the behavior standard of a character, and don't know what the role should do, what shouldn't do or how to do it. The rapid change of society is often the main reason for the unclarity of social roles. Role interruption, referrers that in the role, there is a contradiction between the two roles assumed by one person. The interrupt of the 
roles happens because that when people is taking a role, they didn't prepare for a phase after to assume the role of, or the former has one manners rule which conflicts with the later.

\section{Use Film Analysis to Interpret Role Is Not Clear, Role Interruption}

When she was told that she was a wealthy woman, she had the problem that cannot understand the role and it was interrupted. "I have no money, really no money," she said. "I have a total of $¥ 63.72$ in my bag. Where is my bag? Don't lose it for me." She also doesn't know she needn't open the door or say thanks to the attendant as a rich woman. Of course, she doesn't know the rich should go to look the global market in the morning or watch the cash price, including the euro, the dollar, either. What the rich person should do, what not to do and how to do it, is completely unknown to her, which fully illustrates the social role imbalance caused by the unclear role of the character. Taking on the role of the poor, not prepare for the role of the rich assumed by "Four rounds of dreams", making the code of conduct of the poor role conflicts with behavior required by the rich role, this also reflected the interruption of social roles.

\section{Role Failure}

\section{Show the Relevant Theories}

Role failure is an extremely serious disorder that occurs during role-playing. It is a failure performance of cosplayers due to a variety of reasons, and finally, the roles have to middle end the performance, while no exit role, but has been difficult, each step will encounter more conflicts.

From the results of the failure of the role, there are usually two situations: one is the role of the undertaker who has to withdraw from the role; For example, divorce in modern society increases, as a party, divorce means failure of the role. Anyway, the role of her husband or his wife is not successful, or they won't get divorced. The other is that although it is still in the position of a certain role, its performance has been proved to be a failure. For example, some couples have broken up and separated, although they have not divorced, it is still a failure of role-play.

\section{Use Film Analysis to Interpret the Role Failure}

In the film, Dan played the role of the rich, although there are no roles have to be considered out of the role in the halfway, it appeared another case that its performance has been proved to be a failure in the position of a role. The plot of the most typical is to buy things under the idea that to make the sales happy not the buyer. And she not only use the discount, but also requires the staff to raise the price. Obviously, the behavior is based on the role position of the rich, which is different from the realistic society, so this is a manifestation of the role of failure.

\section{Homework Assignments Allow Students to Use the Film to Analyze the Role Theory}

It is one thing for students to learn knowledge in class, and to digest theoretical knowledge is another. How to apply theoretical knowledge to practice, make theory and practice organically combined, and use the theoretical to guide practice flexibly is the goal of teachers' teaching. In order to further test the extent of the students have mastered the role theory, the author gives students the assignment that they need to review the knowledge of the social role theory on the book and then watch the story 2 kindness in the movie 《Personal Tailor》. Students need to concrete analysis of the film's plot detailed fragment shows in the part of social role theory after watching, the theory includes: the performance of the social role, social role play process, the social role of disorder in this range. It is important for teachers to emphasize the theoretical analysis rather than to make the students comment on the film, which is to avoid students writing assignments as film reviews or impressions.

\section{The Teacher Summarizes the Homework and Helps Students to Strengthen the Theoretical Knowledge of the Role}

The teacher reviews and summarizes the students' homework in class, which is also the process of further helping students to comb and consolidate theory. In movie Personal Tailor, the main theory 
of social roles in part of the story 2 are as follows:

\section{Use Film Analysis to Explain the Classification of Social Roles}

First of all, the role of Fan Wei as the government official should belong to the self-induced role, which is obtained through individual activities and efforts. In addition, the official belong to cadres stipulation role, namely corresponding as what should do and what should not do all have specific provision. For example, they went to the temple of the fragments in the film, in prayer, when he was a role as drivers, worship or not is his freedom, but when he played the role as a leader, he can have only one religion, therefore cannot worship; what's more, the cadres belongs to the expressive role, he is not in order to obtain economic benefits or compensation, but to show the role of social fairness, social justice, such as government officials will need to be the person of integrity, corporate dilettantes. In the film, the role played by Fan Wei is not allowed to accept any gifts or money and other temptation from foreign guests visit, folks seek job, business bribery, beauty temptation; In the end, the government cadres should also belongs to the role of consciousness, when he was in this role, he should clearly realize that they are burdened with certain rights and obligations, and although the corporate dilettantes play the role of the characters in the film did not greedy, but don't handle affairs either, do nothing, so it belongs to a kind of corruption, is also a kind of role failure.

\section{Use Film Analysis to Interpret Social Roles}

\section{The Determination of Social Roles}

The determination of roles referrers to ensure the process that the actual status, identity, capacity and other conditions of a person are consistent and equal to the roles he undertakes. In the movie, before Fan Wei transforms the role, the company has done an important thing for him - determined the role. They have established a "town" level of leadership for Mr Fan. Only by clarifying social roles, can the construction and playing be prepared for the following social roles.

\section{Construction of Roles}

Role construction refers that the role players need to know and understand their roles, and choose the appropriate way to perform. In the film, Fan Wei's role in the construction of his own leadership is not corrupt, he needs to be diligent. Later, the secretary told him that leaders need to read a large number of documents, the guild, understand the sufferings of the people's livelihood, and be the messenger to communicate with all countries on the interview and so on, they construct the role of leadership through a series of actions.

\section{Use Film Analysis to Interpret the Performance of Social Roles}

The performance of social roles requires "scenery and props", "clothes, appearance and manners", "front desk, background and role coordination". Thus, the coordination and performance of the roles are realized.

\section{First, the Setting and Props of the Environment}

To show that Fan Wei is a leading role, he has to have his own office, with large desks, sofas, telephones, filing cabinets and so on. The arrangements are in place and the office of the leader is full of books, all of which are neatly arranged, very precise without too much decoration.

\section{Second, Clothing, Appearance and Mannerism}

In the film, Fan Wei needs to dress up, talk about civilization and have certain authority after becoming a leader. When Fan Wei as drivers got into the office settled by " Four rounds of dreams ", he also has the essence of the driver, so the situation designer Bai said "put on this hurriedly, or you still like a driver." When he changed the Chinese tunic suit, wearing a pair of glasses, temperament immediately from the driver to the leadership, also looks very aura, when he sited in the sofa he may imitate state officials speak way "I have found the feeling of looking for someone with the tube immediately to sit here." In addition, also specially set up two phones, division of labor is very clear, the two phones call the doctor use red, the black used to call secretary, set this property is necessary 
to highlight the situation. Props, clothes, instrument are working, when his secretary criticized his doctor should talk to the leader seriously, he speaking newspeak officer said "oh, serious, I still afford to joke", he has entered the role completely of the leading cadres.

\section{Third, Front, Background and Role Coordination}

In the film, the driver of corporate dilettantes plays in the leadership of the play is on the wine table with businessmen bribing, righteously and passionately said "put your stinking money, to bribe me is impossible, do you think money makes me help you, I make you upset and don't do it for you." The contempt for bribery, the throwing of money on the bribe-payer, shows the integrity of the official. This is his performance in the front role. In this film, the "foreground" and "backstage" switch between the two characters are different from words and actions, each of them is in line with their respective roles. Front desk and background also need to be distinguished between time and place respectively. For example, when corporate dilettantes, he needs out community, his office is the background then, the front desk is to community good to the outside world. In contrast, a foreign country make a messenger come to visit Taiwan before and after they changed, because only set a good reputation in the outside world, will usher in foreign ambassadors to visit, so when visiting the office will be at the front desk. Also, let's feel the social role theory, Erving Goffman once explains that in the social life, the foreground and the background have different behaviors, on different occasions, the behavior is also different. Conform to the social norms of the role behavior. A qualified social member should do what he or she should do and say what they should do and say, and do things in an appropriate manner. In addition, the roles also need to be matched, because it is difficult to complete a comprehensive presentation of a social role in an independent role. Look at the Leader in the film, if it had not been for his secretary's coat-tails, appropriate help in handling affairs, or there is no role to all areas of social interaction, it can't finish the role well only by the role of leader.

\section{Use Film Analysis to Explain Social Role Imbalance}

\section{Analysis of Role Conflicts}

In the film, Fan Wei played a role as a state official, and he had clearly defined his responsibilities and obligations. He should always be in law enforcement, and he does not show any favoritism. But when his rural relatives came to him for help, there was a clash of characters. On the one side, his relatives need help, on the other side, he should do the things under the law enforcement. So he is in the role of the existence of contradictions, also called role tension. This tension is often associated with role norms or values.

Fan Wei plays this role who wanted to do a non-corrupt officials and uprightness, under the planning of "Four rounds of dreams ", he resisted temptations, money to bribe, but ultimately failed to resist sex bribery, which caused the failure of role, and he had to drop out of the role-play. He admitted after exit role playing from the mind really play leadership, some changes have taken place, he thought at this position he will naturally have the ability to distinguish right from wrong, but he forgot the fortress from the internal crack, and he could say those words have tired of the mandarin sincerer, listening more and more sweet flattery. Although he really refused to corruption and bribery, but he failure to resist subordinate" on the relationship between the exceptionally good. In fact, in the role of leadership, we see the role conflict within the role conflict. Played in the role of leader as a national cadre, he knew that he should be integrity, honesty, refuse to beauty, but when faced with so much money, the heart also will be a little fluctuation, when faced with a beauty subordinates Lu moves or keep a certain distance at the beginning, but with the beauty of tenderness, step by step, beautiful fall time heart begins to some resistance. Through these details, we can see the conflict within the role.

\section{Analysis of Role Failure}

Fan Wei plays this role who wanted to do a non-corrupt officials and uprightness, under the planning of "Four rounds of dreams ", he resisted temptations, money to bribe, but ultimately failed to resist sex bribery, which caused the failure of role, and he had to drop out of the role-play. He admitted after 
exit role playing from the mind really play leadership, some changes have taken place, he thought at this position he will naturally have the ability to distinguish right from wrong, but he forgot the fortress from the internal crack, and he could say those words have tired of the mandarin sincerer, listening more and more sweet flattery. Although he really refused to corruption and bribery, but he failure to resist subordinate" on the relationship between the exceptionally good. The role of the Noncorrupt officer failed because the desire of the Non-corrupt officer was reduced.

\section{Conclusion}

To sum up, the film of 《Personal Tailor》showed us a disorder performance of the various roles in life and the social roles played by different people through a series of role play. At the same time, we should learn some knowledge about social roles in the real life in order to cope with the role imbalance, so that we can understand roles, comprehend roles and practice roles correctly even it is not easy for everyone to behave and act according to the rules. What's more, the film also provides a good teaching material for sociology about the role theory, so teachers can make full use of the content of the film shows to explain the theory of social role to students vividly and detailed. And the theoretical analysis also makes teaching become more lively and interesting, and it leads students to participate in classroom teaching, so that the interactivity between teachers and students will be strengthened, it also deepens students' understanding of the social role theory, so that students can better grasp the social role theory.

\section{Acknowledgement}

Paper Description: This paper is funded by Shanghai Ocean University "haiyan talent" training program: A1-0209-15-2000-33.

\section{Bibliography}

[1]Jiang chang .On the social role of man, Philosophy research institute of Hubei University

[2] Zheng hang sheng. A new survey of sociology of sociology (Edition 4), Chinese people's university press (2013) 154-516.

[3]Feng xiao tian.Introduction to sociology, (Edition 2), Huazhong University of science and technology press, 2008--01.

[4] Gove. Self-presentation in daily life, [M]. Zhejiang people's publishing house, 1989. 